Short communication

\title{
The synthesis of biodiesel using copper based metal-organic framework as a catalyst
}

\author{
Tresia Pangestu ${ }^{\mathrm{a}, 1}$, Yosafat Kurniawan ${ }^{\mathrm{a}, 1}$, Felycia Edi Soetaredjo ${ }^{\mathrm{a}, \mathrm{b}, *}$, \\ Shella Permatasari Santoso ${ }^{\mathrm{a}, \mathrm{b}}$, Wenny Irawaty ${ }^{\mathrm{a}}$, Maria Yuliana ${ }^{\mathrm{a}}$, Sandy Budi Hartono ${ }^{\mathrm{a}}$, \\ Suryadi Ismadji ${ }^{\mathrm{a}, \mathrm{b}, *}$ \\ ${ }^{a}$ Department of Chemical Engineering, Widya Mandala Surabaya Catholic University, Kalijudan 37, Surabaya 60114, Indonesia \\ ${ }^{\mathrm{b}}$ Graduate Institute of Applied Science and Technology, National Taiwan University of Science and Technology, No. 43, Sec 4, Keelung Rd, Da'an District, Taipei City, \\ Taiwan
}

\section{A R T I C L E IN F O}

\section{Keywords:}

Metal-organic framework

Copper complex

Tricarboxylic acid

Trimesic acid

Biodiesel

Transesterification

\begin{abstract}
A B S T R A C T
The metal-organic framework (MOF) used as a heterogeneous catalyst for biodiesel production has been produced from the coordination of benzene-1,3,5-tricarboxylic acid (BTc) and divalent copper (Cu). A straightforward solvothermal method with ethanol-water solvent was employed for the production of MOF, and rod-like CuBTc-MOF particles with a unit cell length of $37.12 \mathrm{~nm}$ were obtained. Brunauer-Emmett-Teller (BET) sorption-isotherm characterization revealed that CuBTc holds a surface area of $1085.72 \mathrm{~m}^{2} / \mathrm{g}$ and a total pore volume of $1.68 \mathrm{~cm}^{3} / \mathrm{g}$. The high thermal stability of CuBTc, with a degradation temperature of $303{ }^{\circ} \mathrm{C}$, was confirmed through thermogravimetric analysis (TGA). Other characterizations were also carried out to characterize the CuBTc. Specifically, Fourier transform infrared (FTIR), scanning electron microscopy (SEM), and X-ray diffraction (XRD) analysis. The produced CuBTc-MOF is applied to produce biodiesel from palm oil. The composition in biodiesel was quantified using gas chromatography (GC) analysis. The optimal FAME yield in biodiesel of 91\% was obtained from transesterification using $0.04 \mathrm{~g} \mathrm{CuBTc}$ and methanol to oil volume ratio of 5:1. Recycled CuBTc- MOF was also capable of producing biodiesel with high FAME yield, which is $86 \%$. The obtained result signifies the potential catalytic activity of CuBTc-MOF in the production of biodiesel.
\end{abstract}

\section{Introduction}

The depletion of petroleum reserves and global warming are the main factors to develop renewable and more environmentally friendly energy. The blending of biodiesel with engine fuel has been widely carried out; this practice is especially to reduce the use of non-renewable fossil fuels. Biodiesel is mainly produced by transesterification of triglyceride in biomass-oil (such as vegetable oil and animal fat) with methanol. Biodiesel is considered an environmentally friendly fuel because it produces lower levels of $\mathrm{CO}_{2}, \mathrm{SO}_{x}$, and hydrocarbon emissions [1]. The use of the catalyst in transesterification is significantly affected the reaction rate; the use of catalyst may favor the formation of product over by-product. Over the practices, the use of heterogeneous catalysts is more preferred than a homogeneous catalyst. In the use of homogeneous catalysts, a challenging separation-purification process is required to separate product from catalyst and excess reactant [2]. The use of heterogeneous catalysts offers more advantages over homogeneous catalysts, such as recyclable, ease separation-purification process, high glycerol purity, and not corrosive. The use of heterogeneous catalysts also helps to reduce the total production cost [3]. Furthermore, the presence of water in homogeneous catalysts (either as a solvent and/or attached water) give a depression effect to the catalytic activity of the catalyst; this effect is minimized in the use of heterogeneous catalysts [4].

Heterogeneous catalysts can be alkaline or acidic; the acidic catalyst is used in this study. The advantage of acidic heterogeneous catalyst is that the formation of soap as byproducts is minimized or nil. In this study, the MOF is prepared by combining a bio-derived carboxylic acid ligand, namely benzene-1,3,5-tricarboxylic acid (BTc), with Lewis acid metal, namely copper $(\mathrm{Cu})$. BTc, also known as trimesic acid, offers a beneficial structure as a MOF starting material; it has three carboxylic groups which can form a coordination complex with metal ions. As reported by Giammar and Dzombak (1998), the carboxylic groups of BTc have a pKa value of $3.01,3.71$, and 4.49 , respectively. BTc ligand

\footnotetext{
* Corresponding authors at: Department of Chemical Engineering, Widya Mandala Surabaya Catholic University, Kalijudan 37, Surabaya 60114, Indonesia.

E-mail addresses: felyciae@yahoo.com (F.E. Soetaredjo), suryadiismadji@yahoo.com (S. Ismadji).

${ }^{1}$ These authors contributed equally to this work.
} 
(a)<smiles>O=C(O)c1cc(C(=O)O)cc(C(=O)O)c1</smiles>

(b)<smiles>CCOC(=O)c1cc(C(=O)OC)cc(C(=O)OOOOC(=O)c2cc(C(=O)OOOOC(=O)c3cc(C(=O)OC)cc(C(=O)OC)c3)cc(C(=O)OOOC(=O)c3cc(C(=O)OCC)cc(C(=O)OOC)c3)c2)c1</smiles>

(c)

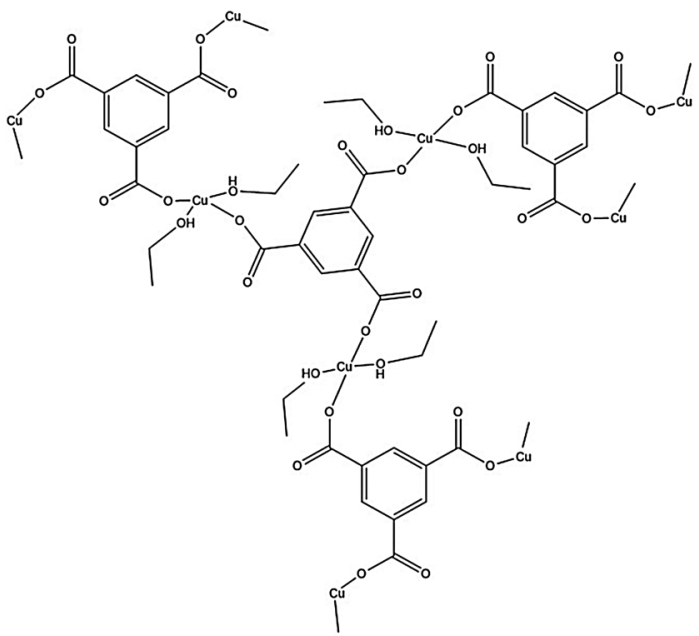

Fig. 1. (a) Cu ions and dissociated BTc molecules in aqueous solution. (b) Schematic structure of CuBTc-MOF in water; and (c) with the presence of ethanol. The molecules/particles in the reaction scheme are partially presented, and water molecules are removed for simplification purposes.

forms a complex with copper (CuBTc) which has a complex formation constant of 2.67 [5]. Reconstruction of species distribution diagram (Supplementary Data Figure S1) from these constants shows that the CuBTc complex is formed in all range of $\mathrm{pH}$ (acidic to alkali) [5], this indicates the possibility of the complex formation.

Many studies have shown the synthesized of CuBTc MOF and its use in various applications, such as being used as an ion exchanger, adsorption agent, reduction agent, and antioxidant agent [6-11]. However, there are still no studies investigating the potential of CuBTc-MOF to catalyze biodiesel production thus far. The CuBTc used in this study is synthesized through a simple method solvothermal method, and the prepared MOF is used as a heterogeneous acid catalyst in the transesterification of palm oil and methanol to produce biodiesel. The effect of catalyst mass, the volume ratio of methanol to oil, and recyclability of MOF as a heterogeneous catalyst is examined.

\section{Methods}

\subsection{Materials}

The chemicals used in this study are copper (II) sulfate pentahydrate (CAS:7758-99-8, 99.995\%purity), benzene-1,3,5-tricarboxylic acid (CAS:554-95-0), ethanol (CAS:64-17-5, 99.8\%purity), methanol
(CAS:67-56-1, $\geq 99.8 \%$ purity), N-hexane (CAS:110-54-3, $\geq 95 \%$ purity). All chemicals were obtained from Sigma Aldrich. The palm cooking oil was obtained from a local supermarket in Surabaya, East Java, Indonesia. All chemicals are used as received without any further purification.

\subsection{Preparation of $\mathrm{CuBTc}-\mathrm{MOF}$}

Copper sulfate pentahydrate $(1.6101 \mathrm{~g})$ was dissolved in $62.5 \mathrm{~mL}$ reverse osmosis water. The copper solution was then added to $1.00 \mathrm{~g}$ BTc in $62.5 \mathrm{~mL}$ of $50 \%(\mathrm{v} / \mathrm{v})$ ethanol. The mixture was continuously stirred for $1 \mathrm{~h}$ before transferred into a sealed autoclave. The mixture was then for $18 \mathrm{~h}$ at $110^{\circ} \mathrm{C}$. The mixture was then cooled slowly to room temperature. The solid MOF formed was separated from the supernatant by using centrifugation. MOF was washed 5 times with $50 \%$ (v/v) ethanol to remove unreacted reactants. Subsequently, MOF was dried in an oven at $100{ }^{\circ} \mathrm{C}$ for $12 \mathrm{~h}$. The scheme of preparation of CuBTc-MOF is presented in Supplementary Data Figure S2.

\subsection{Characterization of $\mathrm{CuBTc}-\mathrm{MOF}$}

The diffraction pattern of CuBTc was analyzed using an X-ray Diffractometer Phillips X'pert with Cu-Ka radiation $(\lambda=1.5406 \AA)$ at 

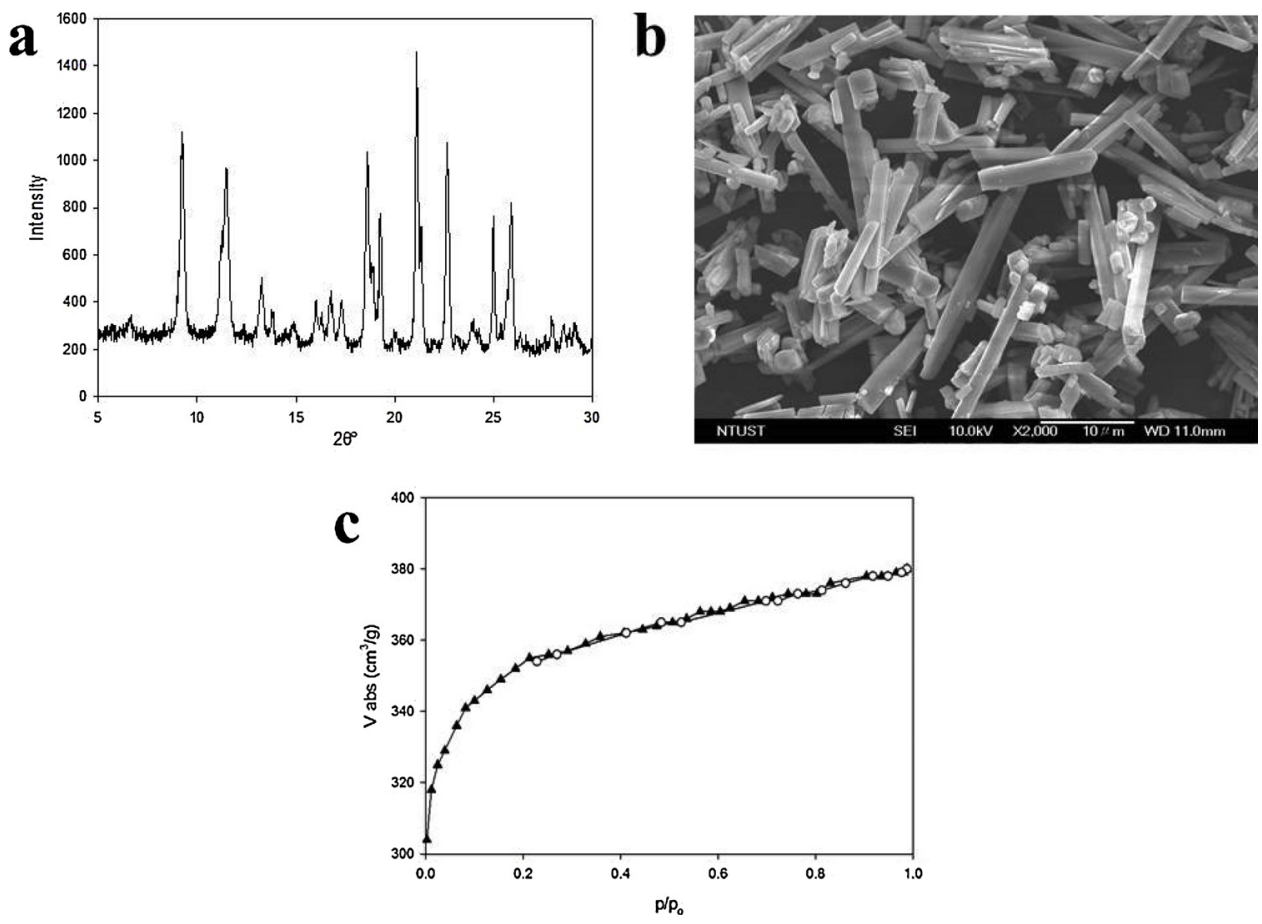

Fig. 2. Characterization of CuBTc-MOF: (a) XRD pattern, (b) SEM image and (c) $\mathrm{N}_{2}$ adsorption-desorption isotherm.

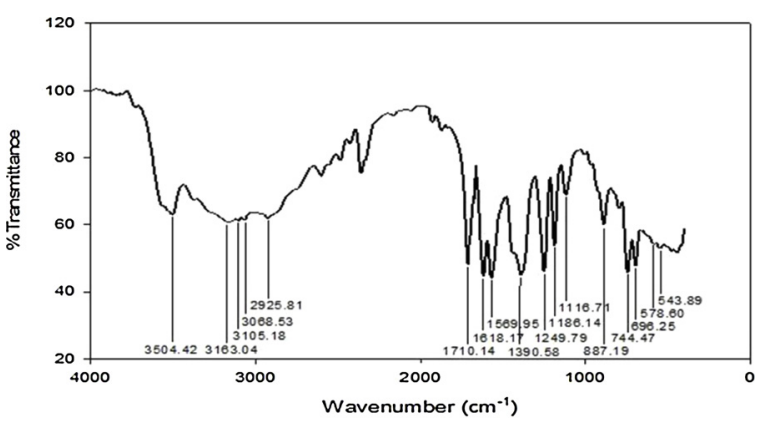

Fig. 3. FTIR spectrum of CuBTc-MOF.

$40 \mathrm{kV}$ and $30 \mathrm{~mA}$. The surface morphology of was analyzed using a JEOL JSM-6500F Field Emission Scanning Electron Microscope. $\mathrm{N}_{2}$ sorption was obtained using a Quantachrome at a temperature of $-195.6^{\circ} \mathrm{C}$. The surface area of Cu-BTC was determined using the multiple-point Brunauer-Emmett-Teller (BET) equation at $\mathrm{p} / \mathrm{p}_{\mathrm{o}}$ range of $0.05-0.3$, and total pore volume was determined at saturation point at $\mathrm{p} / \mathrm{p}_{\mathrm{o}}=0.997$. Thermal stability was analyzed using a TGA system (model SDT 2960 \& Thermal Analyst 2000, TA Instruments). The surface functional groups were analyzed using FTIR with $\mathrm{KBr}$ background; the spectrum was recorded in the range of $400-4000 \mathrm{~cm}^{-1}$.

\subsection{Production of biodiesel}

The transesterification reactions of palm oil using CuBTc as the catalyst was carried out as follows: palm oil $(5 \mathrm{~g})$, methanol $(50 \mathrm{~mL})$, and MOF $(0.04 \mathrm{~g})$ were mixed in a three-neck flask. The mixture was heated at $60^{\circ} \mathrm{C}$ for $4 \mathrm{~h}$. The biodiesel was separated from the mixture (glycerol and unreacted reactants) by dissolving in $75 \mathrm{~mL} n$-hexane. The biodiesel layer was heated at $65^{\circ} \mathrm{C}$ to vaporize $n$-hexane. The used MOF was collected through simple filtration and washed with $n$-hexane to remove oil residue before reused for another transesterification experiment.

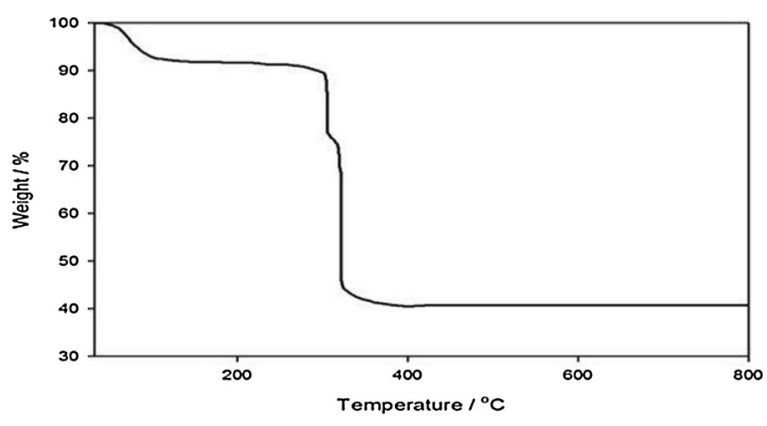

Fig. 4. TGA curve of Cu-BTC MOF.

\subsection{Characterization of biodiesel}

Analysis of fatty acid methyl esters (FAME) content in biodiesel was conducted using a Gas-Chromatography (GC), equipped with SLB-IL 111 column $(30 \mathrm{~m} \times 0.25 \mathrm{~m} \times 0.20 \mu \mathrm{m})$. Helium gas was used as the mobile phase with a flow velocity of $30 \mathrm{~cm} / \mathrm{s}$. The injected sample volume was $1 \mu \mathrm{L}$, with a splitting ratio of 50:1. The oven temperature was maintained at $180^{\circ} \mathrm{C}$. The injection port and detector temperature were set at $250^{\circ} \mathrm{C}$ and $260^{\circ} \mathrm{C}$, respectively.

\section{Results and discussion}

\subsection{The formation mechanism of CuBTc-MOF}

CuBTc-MOF was synthesized by reacting divalent $\mathrm{Cu}$ with BTc ligand in $50 \%$ ethanol solution. Schematically the formation of CuBTcMOF is presented in Fig. 1. The divalent copper present as positively charged ions in the solution $[5,12]$. Meanwhile, BTc ligand, which has low acid dissociation constants, tend to be negatively charged due to deprotonation of $\mathrm{H}^{+}$ions from its carboxyl groups (Fig. 1a). The presence of water functions as a mobile phase which brings $\mathrm{Cu}$ and BTc close to each other; the interaction then occurs due to the charge difference between $\mathrm{Cu}$ and BTc (Fig. 1b). The presence of ethanol molecules helps stabilize CuBTc-MOF network by binding to the $\mathrm{Cu}$ central 


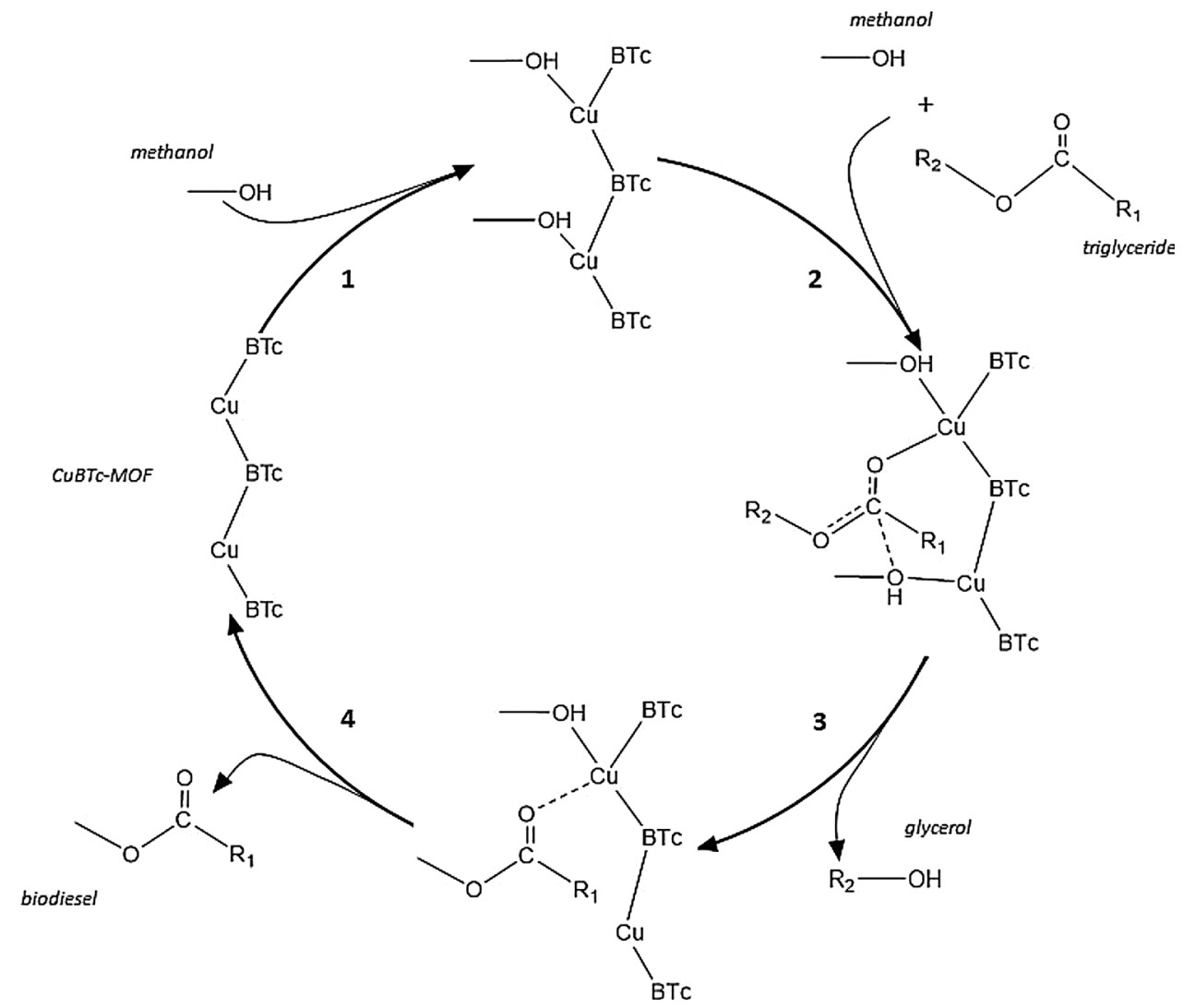

Fig. 5. Transesterification of triglycerides into biodiesel and glycerol by using CuBTc-MOF catalyst. The molecules/particles in the reaction scheme are partially presented, and water molecules are removed for simplification purposes.

Table 1

Fatty acid methyl esters composition of the biodiesel product.

\begin{tabular}{ll}
\hline FAME & Composition, $\%$ \\
\hline C12:0 (Lauric acid methyl ester) & $2.12 \pm 0.10$ \\
C14:0 (Myristic acid methyl ester) & $1.84 \pm 0.06$ \\
C16:0 (Palmitic acid methyl ester) & $42.8 \pm 0.50$ \\
C18:0 (Stearic acid methyl ester) & $3.91 \pm 1.23$ \\
C18:1n9c (Oleic acid methyl ester) & $38.25 \pm 0.81$ \\
C18:2n6c (Linoleic acid methyl ester) & $6.47 \pm 1.25$ \\
\hline
\end{tabular}

atom (Fig. 1c) [13-15]. The ethanol molecules are removed when CuBTc-MOF is dried to obtain dry particles.

\subsection{Characterization of CuBTc-MOF}

As shown in Fig. 3(a), XRD analysis on CuBTc shows a flat baseline; this indicates a high crystalline structure with only a few amorphous regions. The intensive peaks with a tight region were observed at 2 ? of $9.20^{\circ}, 11.48^{\circ}, 13.33^{\circ}, 13.85^{\circ}, 16.10^{\circ}, 16.74^{\circ}, 17.32^{\circ}, 18.63^{\circ}, 19.26^{\circ}$, $21.12^{\circ}, 22.64^{\circ}, 24.99^{\circ}$, and $25.91^{\circ}$. The characteristic XRD peaks of CuBTc show similarities with the published data [16]. The average crystallite unit cell size (D) is determined from the XRD pattern using the Scherrer equation; it is obtained that CuBTc has $\mathrm{D}=37.12 \mathrm{~nm}$.

The morphology of CuBTc is observed by using SEM. As shown in Fig. 2b, the synthesized Cu-BTc has a rod-like shape. The shape of CuBTc is strongly influenced by the polarity of the solvent, and the size of counter ions from the metal salt $[15,17]$. Sahiner et al. (2014) reported that CuBTc synthesized in the presence of water molecules may have a rod-like shape. Furthermore, the morphology of CuBTc is affected by reaction condition, such as temperature. At a moderate temperature $\left(100-110{ }^{\circ} \mathrm{C}\right), \mathrm{CuBTc}$ tend to has a rod-like structure; while at a higher temperature, the shape altered to a round shape [13].
The $\mathrm{N}_{2}$ adsorption-desorption isotherms of the Cu-BTC MOF was analyzed at a temperature of $-195.6{ }^{\circ} \mathrm{C}$. The Brunauer-Emmett-Teller (BET) surface area was calculated at a relative pressure from 0.05 to 0.30; it is obtained that CuBTc has a BET surface area of $1085.72 \mathrm{~m}^{2} / \mathrm{g}$. The total pore volume was determined at the highest relative pressure, which gave the value of $1.68 \mathrm{~cm}^{3} / \mathrm{g}$. These results confirmed that the Cu-BTC MOF had the micro-/meso-/macroporous structure [18]. The synthesized Cu-BTC MOF exhibits the type I adsorption-desorption isotherm with monolayer adsorption and follows the type-H4 hysteresis in the partial pressure range from 0.2 to $1.0\left(\mathrm{P} / \mathrm{P}_{0}\right)$, as shown in Fig. 3(c) [19]. Nitrogen adsorption of MOF usually occurs at low relative pressure where $\mathrm{P} / \mathrm{P}_{0}<0.1$ and an increase in adsorption occur at the range pressure of $0.2-1.0\left(\mathrm{P} / \mathrm{P}_{0}\right)$ [20].

The surface functional groups of CuBTc was confirmed through the FTIR analysis. As shown in Fig. 3, CuBTc possesses broad bands at $3163.04,3105.18$, and $3068.53 \mathrm{~cm}^{-1}$ which corresponding to $\mathrm{C}-\mathrm{H}$ stretch vibrations originate from the aromatic structure of the BTC linker. A sharp peak at $2925.81 \mathrm{~cm}^{-1}$ was corresponding to $\mathrm{C}-\mathrm{H}$ alkane stretching vibration, while a strong peak at $1710.14 \mathrm{~cm}^{-1}$ was due to $\mathrm{C}=\mathrm{O}$ stretching vibration. The medium-weak peaks at 1390.58 , 1569.95 and $1710.14 \mathrm{~cm}^{-1}$ were due to $\mathrm{C}=\mathrm{C}$ stretching vibrations originating from the aromatic structure. The sharp peaks at 1116.71, 1186.14 and $1249.79 \mathrm{~cm}^{-1}$ were due to $\mathrm{C}-\mathrm{O}$ stretching vibrations. The peaks at 543.89 and $578.60 \mathrm{~cm}^{-1}$ indicate the $\mathrm{Cu}-\mathrm{O}$ vibrations, which suggest the formation of the CuBTc-MOF [21].

Thermal gravimetric analysis was conducted at a temperature range of $32.8-800{ }^{\circ} \mathrm{C}$ prior to determine the thermal stability of CuBTc. From Fig. 4 , it can be seen that a weight loss $(\sim 8 \mathrm{wt} \%)$ begins in the temperature range of $32.8-134^{\circ} \mathrm{C}$, which is due to the evaporation of free moisture. The CuBTc is thermally stable in the temperature range of 134- $303{ }^{\circ} \mathrm{C}$; it is evident that the structure of MOF is quite stable since weight loss of MOF is not significant. After $303^{\circ} \mathrm{C}$, the second stage 

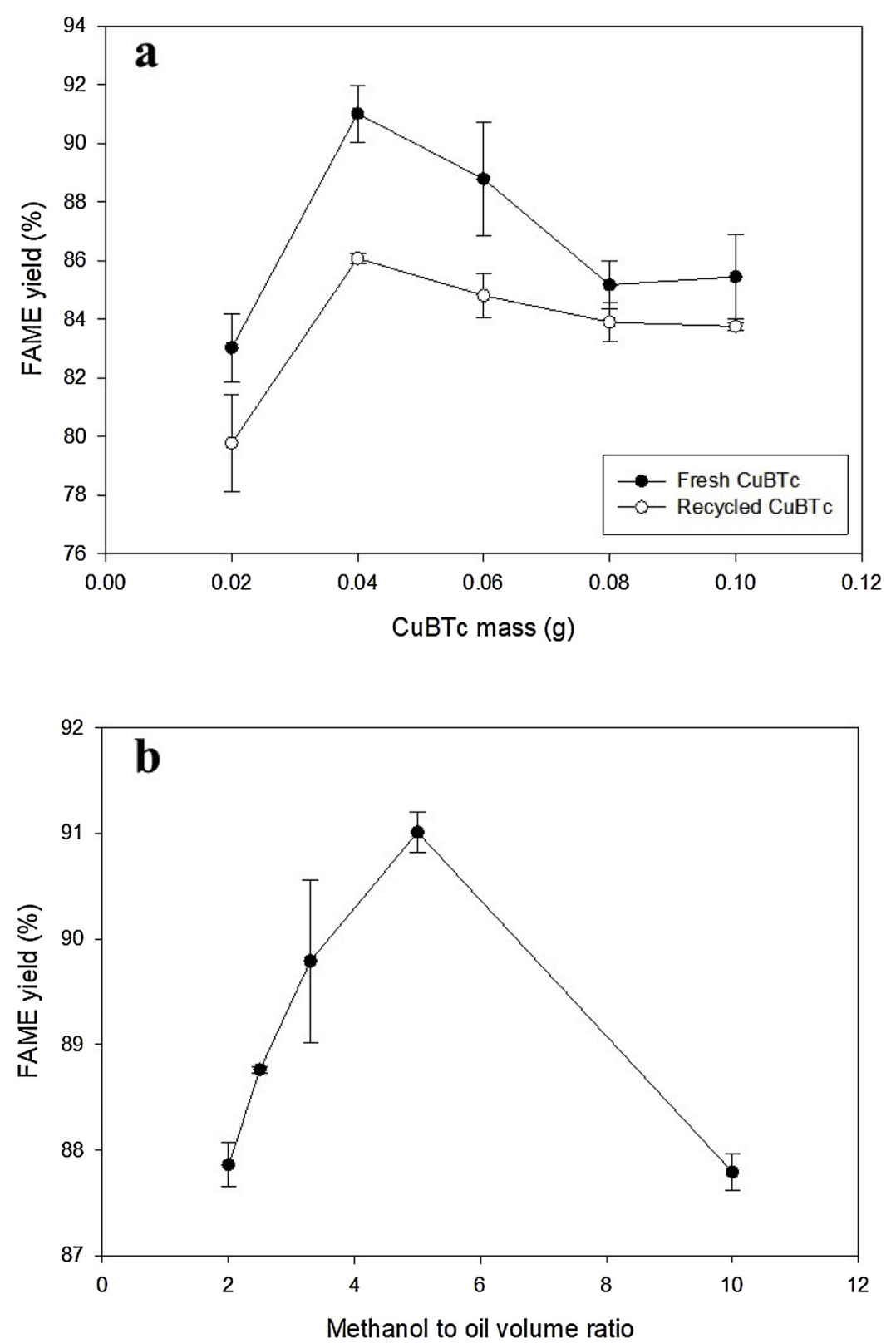

Fig. 6. Influence of (a) catalyst and (b) methanol amount in biodiesel (FAME) yield. Reaction conditions (a) 10:2 MeOH:oil volume ratio; (b) 0.04 g CuBTc.

weight loss occurs, which signify by a drastic decrease in weight up to $43 \mathrm{wt} \%$. This phenomenon indicates the damage of the BTc linker. The constant weight was observed at a temperature greater than $387^{\circ} \mathrm{C}$, indicating that entire BTc linker was degraded and only $\mathrm{CuO}$ and $\mathrm{Cu}_{2} \mathrm{O}$ residue remained [16].

\subsection{Biodiesel production mechanism by using CuBTc catalyst}

CuBTc-MOF was used as the Lewis acid catalyst in the transesterification of triglycerides into biodiesel. The transesterification mechanism steps are schematically presented in Fig. 5. As a Lewis acid catalyst, CuBTc provides unsaturated open sites that readily coordinate with methanol and triglycerides. Theoretically, the transesterification is assisted by several forces, including interface dipole [22,23], electron delocalization [24], and nucleophilic attack [25,26]. The explanation of the steps in detail is as follows:

Step 1: Methanol molecules establish coordination with the central $\mathrm{Cu}$ atoms of the $\mathrm{CuBTc}$ particles. Coordination is induced by the presence of surface metal dipoles which promote interface dipole-dipole interaction.

Step 2: Triglyceride molecule attach to the central $\mathrm{Cu}$ atom of the CuBTc particle. The interaction is promoted by delocalization of electron, which forms a resonance between two oxygen atoms of the triglyceride.

Step 3: Methanol and triglyceride have positions that are close to each other so that their interaction can occur facilely. The nucleophilic oxygen atom from methanol hydroxyl group then attacks the electrophilic carbon at the triglyceride ester group thus transesterification occurs. The nucleophilic attack produces glycerol by-product.

Step 4: The produced biodiesel detached from the CuBTc through electron delocalization at the oxygen atoms; thus, the main product of biodiesel is obtained.

The produced biodiesel was then analyzed for its composition by using gas chromatography analysis. It is shown that there are six FAMEs contained in biodiesel product, which showed by six major chromatography peaks between 2.37 and 3.97 min (Table 1).

The identified compounds are lauric acid methyl ester $\left(\mathrm{C}_{13} \mathrm{H}_{26} \mathrm{O}_{2}\right)$, myristic acid methyl ester $\left(\mathrm{C}_{15} \mathrm{H}_{30} \mathrm{O}_{2}\right)$, palmitic acid methyl ester 

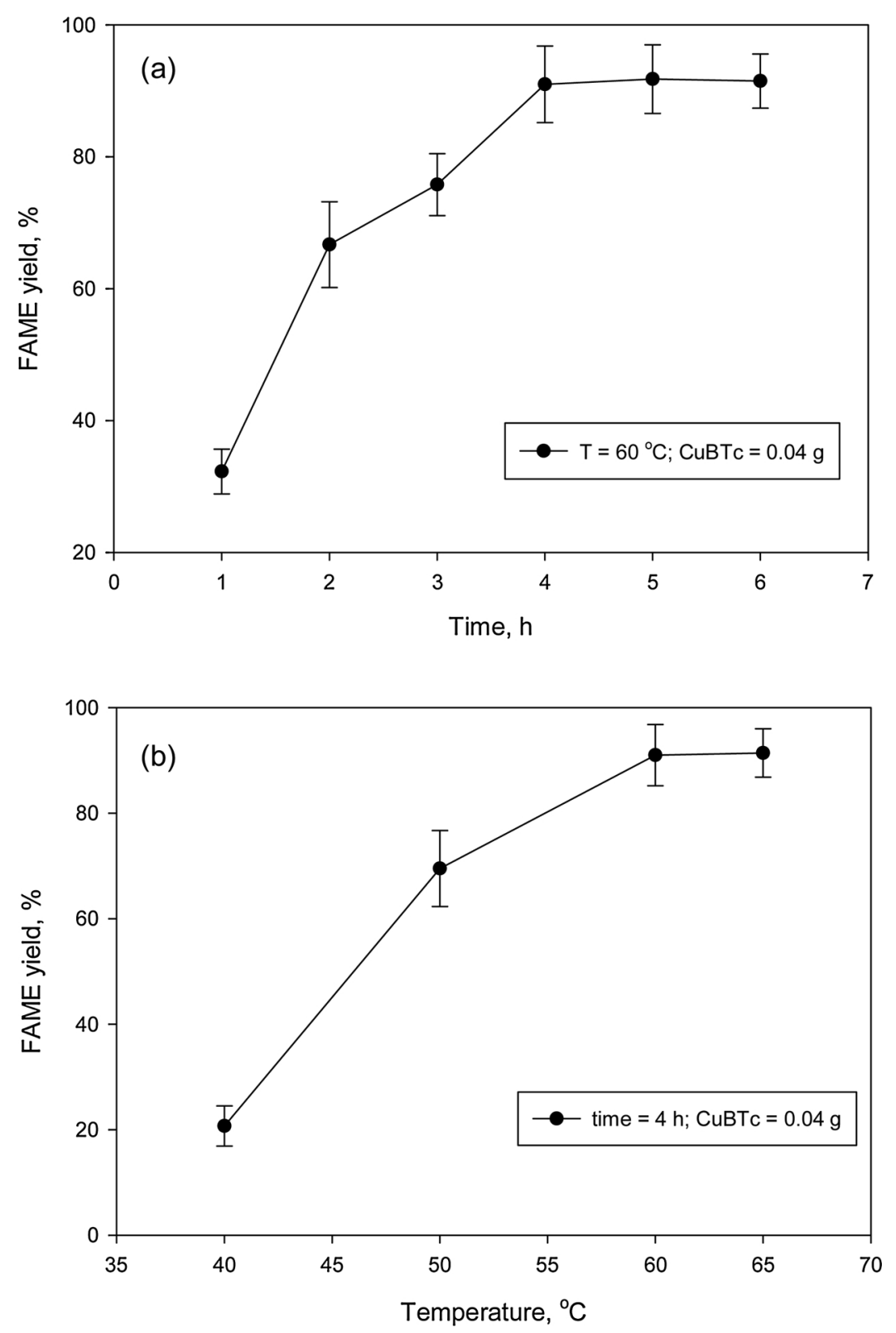

Fig. 7. The influence of (a) reaction time, and (b) reaction temperature on the yield of biodiesel (FAME).

$\left(\mathrm{C}_{17} \mathrm{H}_{34} \mathrm{O}_{2}\right)$, stearic acid methyl ester $\left(\mathrm{C}_{19} \mathrm{H}_{38} \mathrm{O}_{2}\right)$, oleic acid methyl ester $\left(\mathrm{C}_{19} \mathrm{H}_{36} \mathrm{O}_{2}\right)$ and linoleic acid methyl ester $\left(\mathrm{C}_{19} \mathrm{H}_{34} \mathrm{O}_{2}\right)$. The palmitic and oleic methyl ester was the highest contained in FAME, where the yields were $42.8 \%$ and $38.25 \%$, respectively. The total content of FAME is $95.39 \%$.

\subsection{Recyclability and the effect of the amount of CuBTc, methanol, reaction time, and reaction temperature in biodiesel production}

Recyclability is an attractive factor in the use of catalysts. Used CuBTc-MOF is regenerated by removing the oil residue using fresh nhexane. The ability of recycled CuBTc-MOF in the transesterification process is investigated. As shown in Fig. 6(a), the transesterification process by using $0.04 \mathrm{~g}$ of fresh CuBTc is able to yield 91\% of FAME; while, the recycled CuBTc can yield $86 \%$ of FAME. This result proves that the CuBTc catalytic activity only slightly decreases, but the biodiesel yield still high even though it has undergone a regeneration process.

The amount of CuBTc MOF used in transesterification gives significant influence to the FAME yield. The increase of the amount of catalyst provides more active sites for the transesterification reaction of triglyceride and methanol, leading to an increase in the yield of FAME. It can be seen from Fig. 6(a) that the optimum FAME yield was reached by using $0.04 \mathrm{~g}$ of fresh or recycled CuBTc. The higher amount of CuBTc used causes a decrease in FAME yield. The use of CuBTc greater than $0.04 \mathrm{~g}$ does not favor the transesterification process due to the dispersion of active centers and retard the molecular interactions between the reactants and active sites (partial coverage), and it decreases the reaction between triglycerides and methanol to produce FAME [27]. The maximum yield of FAME (91\% using fresh CuBTc) obtained in this study is higher than the reported research using some common catalysts, namely $\mathrm{NaOH}$ as a homogeneous catalyst [11]. The use of CuBTc as a catalyst in transesterification provides more advantages, such as higher yield of FAME, a straightforward separation process, and lower production cost.

The amount of methanol used in transesterification is usually given in excess amounts so that the reaction shifts toward the product side $[25,28,29]$. Although the yield of biodiesel may increase as methanol 
increased, the exaggerating amount of methanol also causes an increase in glycerol production. This may provoke a back reaction to the reactant side since transesterification is a reversible reaction. As depicted in Fig. 6(b), the FAME yield increases with increasing of $\mathrm{MeOH}$ to oil volume ratio from 2:1 to 5:1; the FAME yield then decreases as the ratio further increased to 10:1. This result suggests that excessive methanol usage does not favor transesterification. Moreover, an excessive amount of methanol gives several disadvantages such as high production cost and also cause higher solubility of glycerol in methyl ester that could complicate the separation of biodiesel and glycerol [30].

The effect of reaction time and temperature on the FAME yield during the production of biodiesel using CuBTc as the catalyst is given in Fig. 7.

The effect of reaction time on the yield of biodiesel was studied at the temperature of $60^{\circ} \mathrm{C}$ and the amount of BTc $0.04 \mathrm{~g}$. The yield of biodiesel increased with the increase of reaction time (1-4h) as seen in Fig. 7(a). Longer reaction time provide more time for the reactants to diffuse into the internal interior of the catalyst (where the reaction take place), and for the catalyst itself, it provides more time to adsorp the reactants and desorp the product of the reaction. Therefore, the longer the reaction time, more and more reactants could diffuse into the catalyst molecules, resulting in a higher conversion of the reactants and the yield of the FAME product. After $4 \mathrm{~h}$, a further increase in reaction time gave no significant influence on the yield of FAME; this phenomenon indicates that $4 \mathrm{~h}$ is best reaction time to produce biodiesel using CuBTC as the catalyst.

The influence of the reaction temperature on the yield of FAME is depicted in Fig. 7(b). The temperature gave a positive effect on the yield of FAME. The transesterification reaction between triglycerides and methanol is an endothermic and reversible process. The increase in temperature increases the reaction rate constant and will shift the reaction into the products side. The mass transfer barrier between the catalyst and reactants decrease with the increase of temperature, and as a result, the adsorption rate of reactants into the surface of the catalyst becomes faster leading to the faster diffusion of the reactants into the pore of catalyst. This phenomenon will increase the yield of FAME. At temperature $65^{\circ} \mathrm{C}$, the yield of FAME around $90.4 \%$. Since the increase of reaction temperature from 60 to $65^{\circ} \mathrm{C}$ only increase the yield around $0.4 \%$, and for energy consideration, the temperature of $60^{\circ} \mathrm{C}$ was chosen as the optimum temperature for the biodiesel production using CuBTc as a catalyst.

A comparison of the FAME yield/conversion produced using CuBTc as a catalyst with other studies using MOFs and its modified forms as catalysts are given in Table 2. In general, CuBTc has comparable catalytic activity with those MOFs catalysts which available in the literature. Even without modification, CuBTc gave excellent catalytic capability, a yield of FAME above $90 \%$ is the evidence.

\section{Conclusions}

The CuBTc-MOF was successfully synthesized using a facile solvothermal method with $50 \mathrm{v} \%$ ethanol solvent. The CuBTc-MOF particles have a rod-like shape, a large BET surface area, and good thermal stability. The $\mathrm{N}_{2}$ sorption isotherm shows that CuBTc possesses type I sorption isotherm with an $\mathrm{H} 4$ hysteresis. The CuBTc-MOF shows great catalytic activity in the transesterification process to produce biodiesel (FAME); it is functioned as a Lewis acid catalyst. The optimum yield of FAME was reached with the use of $0.04 \mathrm{~g}$ CuBTc and MeOH: oil volume ratio of $5: 1$. The CuBTc also able to recycle without losing the catalytic activity.

\section{Conflicts of interest}

The authors declare no conflict of interest. 


\section{Acknowledgments}

Financial support from the Indonesia Ministry of Research and Technology and Higher Education through World Class Research with the contract no 200J/WM01.5/N/2019 is highly appreciated.

\section{Appendix A. Supplementary data}

Supplementary data associated with this article can be found, in the online version, at https://doi.org/10.1016/j.jece.2019.103277.

\section{References}

[1] F.G. Cirujano, A. Corma, Xamena FXLi, Zirconium-containing metal organic frameworks as solid acid catalysts for the esterification of free fatty acids: synthesis of biodiesel and other compounds of interest, Catal. Today 257 (2015) 213-220.

[2] D.Y.C. Leung, X. Wu, M.K.H. Leung, A review on biodiesel production using catalyzed transesterification, Appl. Energy 87 (2010) 1083-1095.

[3] D.M. Alonso, R. Mariscal, R. Moreno-Tost, M.D.Z. Poves, M.L. Granados, Potassium leaching during triglyceride transesterification using $\mathrm{K} / \gamma-\mathrm{Al}_{2} \mathrm{O}_{3}$ catalysts, Catal. Commun. 8 (2007) 2074-2080.

[4] K. Narasimharao, A. Lee, K. Wilson, Catalysts in production of biodiesel: a review, J. Biobased Mater. Bioenergy 1 (2007) 1-12.

[5] D.E. Giammar, D.A. Dzombak, Copper complexation with the mellitic acid series, J. Sol. Chem. 27 (1998) 89-105.

[6] S. Wang, W. Deng, L. Yang, Y. Tan, Q. Xie, S. Yao, Copper-based metal-organic framework nanoparticles with peroxidase-like activity for sensitive colorimetric detection of Staphylococcus aureus, Appl. Mater. Interfaces 9 (2017) 24440-24445.

[7] F.-H. Wei, D. Chen, Z. Liang, S.-Q. Zhao, Y. Luo, Synthesis and characterization of metal-organic frameworks fabricated by microwave-assisted ball milling for adsorptive removal of Congo red from aqueous solutions, RSC Adv. 7 (2017) $46520-46528$.

[8] F. Wu, L.-G. Qiu, F. Ke, X. Jiang, Copper nanoparticles embedded in metal-organic framework MIL-101(Cr) as a high performance catalyst for reduction of aromatic nitro compounds, Inorg. Chem. Commun. 32 (2013) 5-8.

[9] J. Cejka, Metal-organic frameworks. Applications from catalysis to gas storage, Angew Chem. Int. Ed. 51 (2012) 4782-4783.

[10] B. Panella, M. Hirscher, H. Putter, U. Muller, Hydrogen adsorption in metal-organic frameworks: Cu-MOFs and Zn-MOFs compared, Adv. Funct. Mater. 16 (2016) 520-524.

[11] X. Meng, G. Chen, Y. Wang, Biodiesel production from waste cooking oil via alkali catalyst and its engine test, Fuel Process. Technol. 89 (2008) 851-857.

[12] H. Furukawa, K.E. Cordova, M. O'Keeffe, O.M. Yaghi, The chemistry and applications of metal-organic frameworks, Science 6149 (2013).

[13] K.S. Lin, A.K. Adhikari, C.N. Ku, C.L. Chiang, H. Kuo, Synthesis and characterization of porous HKUST-1 metal organic frameworks for hydrogen storage, Int. J. Hydrog. Energy 37 (2012) 13865-13871.

[14] A.S. Münch, F.O.R.L. Mertens, The Lewis acidic and basic character of the internal HKUST-1 surface determined by inverse gas chromatography, Cryst. Eng. Commun. 17 (2015) 438-447.

[15] N. Sahiner, K. Sel, O.F. Ozturk, S. Demirci, G. Terzi, Facile synthesis and characterization of trimesic acid-Cu based metalorganic frameworks, Appl. Surf. Sci.
314 (2014) 663-669.

[16] S. Zhang, H. Liu, C. Sun, P. Liu, L. Li, Z. Yang, X. Feng, F. Huo, X. Lu, CuO/ $\mathrm{Cu}_{2} \mathrm{O}$ porous composites: shape and composition controllable fabrication inherited from metal-organic frameworks and further application in CO oxidation†, J. Mater. Chem. A 3 (2015) 5294.

[17] L.W. Aguiar, Silva CTPd, Lima HHCd, M.P. Moises, A.W. Rinaldi, Evaluation of the synthetic methods for preparing metal-organic frameworks with transition metals, AIMS Mater. Sci. 5 (2018) 467-478.

[18] Y. Zhou, J. Long, Y. Li, Ni-based catalysts derived from a metal-organic framework for selective oxidation of alkanes, Chin. J. Catal. 37 (2016) 955-962.

[19] A. Maleki, B. Hayati, M. Naghizadeh, S.W. Joo, Adsorption of hexavalent chromium by metal-organic frameworks from aqueous solution, J. Ind. Eng. Chem. 28 (2015) $211-216$.

[20] N. Iqbal, X. Wang, J. Yu, N. Jabeen, H. Ullah, B. Ding, In situ synthesis of carbon nanotube doped metal-organic frameworks for $\mathrm{CO}_{2}$ capture, RSC Adv. 6 (2016) $4328-4386$.

[21] V.V.T. Padil, M. Černík, Green synthesis of copper oxide nanoparticles using gum karaya as a biotemplate and their antibacterial application, Int. J. Nanomed. 8 (2013) 889-898.

[22] X. Crispin, V. Geskin, A. Crispin, J. Cornil, R. Lazzaroni, W.R. Salaneck, J.-L. Brédas, Characterization of the interface dipole at organic/metal interfaces, J. Am. Chem. Soc. 124 (2002) 8131-8141.

[23] Z. Hu, Z. Zhong, K. Zhang, Z. Hu, C. Song, F. Huang, J. Peng, J. Wang, Y. Cao, Dipole formation at organic/metal interfaces with pre-deposited and post-deposited metal, NPG Asia Mater. 9 (2017) e379.

[24] R. Herges, D. Geuenich, Delocalization of electrons in molecules, J. Phys. Chem. A 105 (2001) 3214-3220.

[25] N.K. Patel, S.N. Shah, Biodiesel from plant oils, in: S. Ahuja (Ed.), Food, Energy, and Water: The Chemistry Connection, Elsevier, 2015, pp. 277-307.

[26] S.M. Coman, V.I. Parvulescu, Heterogeneous catalysis for biodiesel production, in: K.S. Triantafyllidis, A.A. Lappas, M. Stöcker (Eds.), The Role of Catalysis for the Sustainable Production of Bio-fuels and Bio-chemicals, Elsevier, 2013, pp. 93-136.

[27] M. Han, Y. Li, Z. Gu, H. Shi, C. Chen, Q. Wang, H. Wan, G. Guan, Immobilization of thiol-functionalized ionic liquids onto the surface of MIL-101(Cr) frameworks by SeCr coordination bond for biodiesel production, Colloid. Surf. A 553 (2018) $593-600$.

[28] J.F.G.N. Sanchez, J.M. Encinar, G. Martinez, Biodiesel production from castor oil under subcritical methanol conditions, Int. J. Environ. Sci. Develop. 6 (2015) $61-66$.

[29] U. Rashid, S. Soltani, S.I. Al-Resayes, I.A. Nehdi, Metal oxide catalysts for biodiesel production, in: Y. Wu (Ed.), Metal Oxides in Energy Technologies, Elsevier, 2018, pp. 303-319.

[30] A. Hayyan, F.S. Mjalli, M.A. Hashim, M. Hayyan, I.M. AlNashef, S.M. Al-Zahrani, M.A. Al-Saadi, Ethanesulfonic acid-based esterification of industrial acidic crude palm oil for biodiesel production, Bioresour. Technol. 102 (2011) 9564-9570.

[31] H.M.A. Hassan, M.A. Betiha, S.K. Mohamed, E.A. El-Sharkawy, E.A. Ahmed, Salen$\mathrm{Zr}$ (IV) complex grafted into amine-tagged MIL-101(Cr) as a robust multifunctional catalyst for biodiesel production and organic transformation reactions, Appl. Surf. Sci. 412 (2017) 394-404.

[32] H. Li, F. Liu, X. Ma, Z. Wu, Y. Li, L. Zhang, Z. Zhou, Y. Helian, Catalytic performance of strontium oxide supported by MIL-100(Fe) derivate as transesterification catalyst for biodiesel production, Energy Conv. Manag. 180 (2019) 401-410.

[33] Y. Jeon, W.S. Chi, J. Hwang, D.H. Kim, J.H. Kim, Y.G. Shul, Core-shell nanostructured heteropoly acid-functionalized metal-organic frameworks: bifunctional heterogeneous catalyst for efficient biodiesel production, Appl. Catal. B: Environ. 242 (2019) 51-59. 